\title{
OPTIMASI METODA CV-AAS UNTUK ANALISIS RAKSA(II)
}

\author{
M T Melkhias Aloysius, Gunawan
}

Laboratorium Kimia Analitik Jurusan Kimia

F MIPA Universitas Diponegoro Semarang 50275

\begin{abstract}
ABSTRAK
Telah dilakukan optimasi metoda spektrometri serapan atom-uap dingin atau cold vapour-atomic absorption spectrometry (CV-AAS) untuk analisis raksa(II). Gas atom raksa(0) yang dihasilkan dari reduksi $50 \mathrm{~mL}$ raksa(II) $50 \mathrm{ppb}$ dengan $\mathrm{SnCl} \mathrm{L}_{2}$ $5 \%$ dalam lingkungan asam klorida, ditentukan respon analitiknya dengan kuat arus lampu katoda cekung $4 \mathrm{mAdan}$ pada panjang gelombang $254,1 \mathrm{~nm}$. Kondisi optimum yang diperoleh adalah volume $\mathrm{SnCl}_{2} 5 \%$ sebanyak $1,5 \mathrm{~mL}$; waktu pengadukan 2 menit; lingkungan asam $5 \mathrm{~mL} \mathrm{HCl} 15 \%$ dan kecepatan pompa penghisap 0,3 L/menit.
\end{abstract}

Kata Kunci: Raksa(II), CV-AAS, reduksi

\begin{abstract}
The optimation of cold vapour-atomic absorption spectrometry to analyze mercury(II) had been done. Mercury atomic gases (O) produced from reduction of $50 \mathrm{~mL}$ mercury(II) $50 \mathrm{ppb}$ with $\mathrm{SnCl}_{2} 5 \%$ in acidic solution was determined their analytical respons with hollow cathode lamp's current of $4 \mathrm{~mA}$ and at the wavelength of $254.1 \mathrm{~nm}$. The optimum conditions covered $1.5 \mathrm{~mL}$ volume of $\mathrm{SnCl}_{2} 5 \%$; stirring time 2 minutes; $5 \mathrm{~mL}$ of $\mathrm{HCl} 15 \%$ and the rate of circulating pump of 0.3 L/minutes.
\end{abstract}

Keywords: $\operatorname{Mercury}(I I), C V-A A S$, reduction

\section{PENDAHULUAN}

Prinsip dasar spektroskopi serapan atom adalah interaksi energi radiasi elektromagnetik dengan spesies atom yang dapat menyerap energi radiasi. Interaksi ini dapat menurunkan energi radiasi sehingga Hukum Beer dapat berlaku pula dalam metoda ini. Dalam spektrometri serapan atom proses atomisasi dapat dilaksanakan dengan metoda atomisasi nyala, tungku elektrotermal (sampel dengan jumlah sedikit), pembentukan uap dingin raksa $(\mathrm{Hg})$ dan pembentukan hidrida yang volatil (As, Bi, Ge, Sb, Se dan Te) (Skoog, 1985).

Atomisasi dengan teknik pembentukan uap, dilakukan untuk analisis unsur raksa (pembentukan uap dingin raksa). Pembentukan uap dingin raksa didasarkan pada sifat unsur raksa yang dapat menguap dalam suhu kamar, sehingga atom-atom raksa tersebut dapat diinteraksikan dengan gelombang elektromagnetik untuk menghasilkan absorbansi. Teknik pembentukan uap dingin raksa yang mudah dikerjakan adalah dengan mereduksi sampel yang mengandung raksa menggunakan $\mathrm{SnCl}_{2}$ dalam suasana asam. Uap raksa yang terbentuk kemudian dialirkan ke dalam sel serapan untuk dianalisis.

Metoda CV-AAS ini pertama kali diperkenalkan oleh Hatch dan Ott (Chou dan Naleway, 1984). Raksa anorganik dalam air limbah telah ditentukan oleh ElAwady dkk (1976). May dkk (1987) menetapkan rasio raksa metil terhadap raksa total dalam rantai makanan perairan.

Pemeriksaan raksa total dalam limbah cair secara berkesinambungan dengan metoda CV-AAS telah dilakukan oleh Goto dkk (1982) dan Doolan (1982) dalam batubara serta.Powell (1983) dalam burung dan kelelawar. Dalam penelitian ini dilakukan optimasi metoda CV-AAS untuk analisis raksa(II) karena mempertimbangkan kondisi lapangan yang berbeda. Hasil optimasi tersebut selanjutnya diharapkan dapat digunakan untuk analisis spesies raksa organik dan anorganik dengan perlakuan awal lebih dahulu.

\section{BAHAN DAN ALAT}

Bahan: $\mathrm{HgCl}_{2}, \mathrm{SnCl}_{2}, \mathrm{HCl}, \mathrm{KMnO}_{4}$ semuanya dalam standar pro analisis (E.Merck).

Alat: disain alat seperti pada gambar di bawah ini :

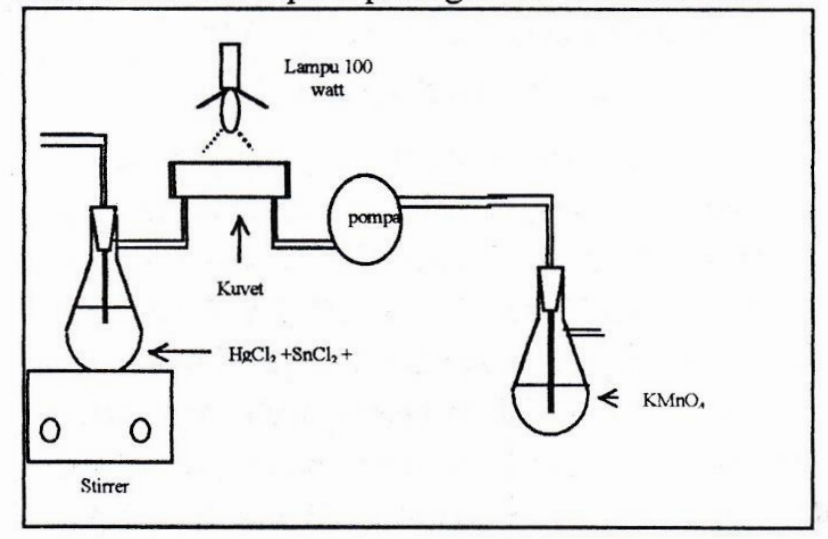




\section{METODA PENELITIAN}

\section{Variasi VolumeSnCl2 5\%.}

Lima puluh mililiter raksa(II) 50 ppb direaksikan dengan $\mathrm{SnCl}_{2} 5 \%$ dengan volume yang divariasi (1 sampai dengan $5 \mathrm{~mL}$.) dan $\mathrm{HCl} 5 \%$ sebanyak $5 \mathrm{~mL}$ di dalam erlenmeyer sebagai pembangkit gas raksa(0).

Kondisi lain :

Kuat Arus Lampu Katoda Cekung $=4 \mathrm{~mA}$

Kecepatan Pompa Penghisap $=1,0 \mathrm{~L} / \mathrm{menit}$

Panjang Gelombang $=254,1 \mathrm{~nm}$

Waktu Pengadukan $=1$ menit

Respon analitik diamati pada recorder AAS

\section{Variasi Waktu Pengadukan}

Lima puluh mililiter raksa(II) 50 ppb direaksikan dengan $\mathrm{SnCl}_{2} 5 \%$ dengan volume yang optimum (hasil variasi Volume $\mathrm{SnCl}_{2} 5 \%$ ) dan $\mathrm{HCl} 5 \%$ sebanyak $5 \mathrm{~mL}$ di dalam erlenmeyer sebagai pembangkit gas raksa(0). Kemudian diaduk dengan pengaduk magnet dengan waktu pengadukan yang divariasi dari $1 \mathrm{~s} / \mathrm{d} 6$ menit. Kondisi lain :

Kuat Arus Lampu Katoda Cekung $=4 \mathrm{~mA}$

Kecepatan Pompa Penghisap $=1,0 \mathrm{~L} /$ menit

Panjang Gelombang $=254,1 \mathrm{~nm}$

Respon analitik diamati pada recorder AAS

\section{Variasi Kadar $\mathrm{HCl}$}

Lima puluh mililiter raksa(II) $50 \mathrm{ppb}$ direaksikan dengan $\mathrm{SnCl}_{2} 5 \%$ dengan volume yang optimum (hasil variasi Volume $\mathrm{SnCl}_{2} 5 \%$ ) dan $\mathrm{HCl}$ dengan kadar yang divariasi $(5 \mathrm{~s} / \mathrm{d} 50 \%)$ di dalam erlenmeyer sebagai pembangkit gas raksa(0). Kemudian diaduk dengan pengaduk magnet dengan waktu pengadukan yang optimum (Hasil Variasi Waktu Pengadukan).

Kondisi lain:

Kuat Arus Lampu Katoda Cekung $=4 \mathrm{~mA}$

Kecepatan Pompa Penghisap $=1,0 \mathrm{~L} /$ menit

Panjang Gelombang $=254,1 \mathrm{~nm}$

Respon analitik diamati pada recorder AAS

\section{Variasi Kecepatan Pompa Penghisap}

Lima puluh mililiter raksa(II) 50 ppb direaksikan dengan $\mathrm{SnCl}_{2} 5 \%$ dengan volume yang optimum (hasil variasi volume $\mathrm{SnCl}_{2} 5 \%$ ) dan $\mathrm{HCl}$ dengan kadar yang optimum (Hasil Variasi Kadar HCL) di dalam erlenmeyer sebagai pembangkit gas raksa(0). Kemudian diaduk dengan pengaduk magnet dengan waktu pengadukan yang optimum (hasil variasi waktu pengadukan) Gas atom raksa $(0)$ yang terbentuk dihisap dengan pom- pa supaya melewati kuvet AAS dengan kecepatan pengadukan yang divariasi $(0,3 \mathrm{~s} / \mathrm{d} 2,5 \mathrm{~L} /$ menit $)$

Kondisi lain :

Kuat Arus Lampu Katoda Cekung $=4 \mathrm{~mA}$

Panjang Gelombang $=254,1 \mathrm{~nm}$

Respon analitik diamati pada recorder AAS

\section{HASIL DAN PEMBAHASAN}

Hasil yang diperoleh pada variasi volume $\mathrm{SnCl}_{2} 5 \%$ disajikan pada tabel 1 dan gambar 1 .

Tabel 1. Hasil respon analitik gas raksa (0) pada variasi volume $\mathrm{SnCl}_{2} 5 \%$

\begin{tabular}{|c|c|}
\hline VOLUME $\mathrm{SnCl}_{\mathbf{2}} \mathbf{5} \%(\mathrm{~mL})$ & RESPON ANALITIK \\
\hline 1 & 313183 \\
\hline 2 & 327645 \\
\hline 3 & 294020 \\
\hline 4 & 316410 \\
\hline 5 & 229503 \\
\hline
\end{tabular}

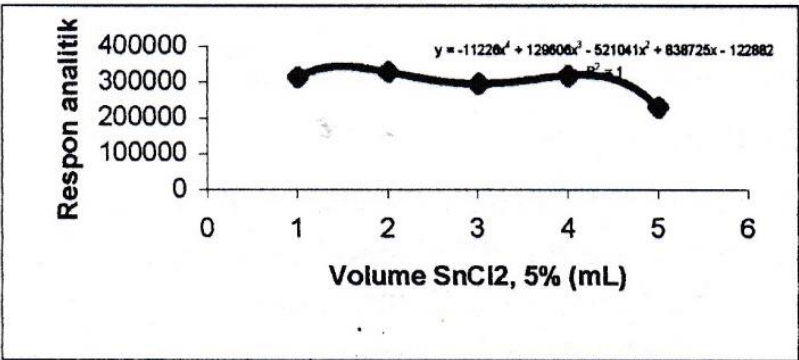

Gambar 1. Hasil respon analitik gas raksa (0) pada variasi volume $\mathrm{SnCl} 25 \%$.

Dari kurva pada gambar 1 diperoleh volume $\mathrm{SnCl}_{2}$ $5 \%$ optimum sebesar $1,5 \mathrm{~mL}$. Hasil yang diperoleh pada variasi waktu pengadukan disajikan pada tabel 2 .

Tabel 2. Hasil respon analitik gas raksa (0) pada variasi waktu pengadukan

\begin{tabular}{|c|c|}
\hline $\begin{array}{c}\text { WAKTU PENGADUKAN } \\
\text { (MENIT) }\end{array}$ & RESPON ANALITIK \\
\hline 1 & 356465 \\
\hline 2 & 376983 \\
\hline 4 & 332355 \\
\hline 6 & 337480 \\
\hline
\end{tabular}

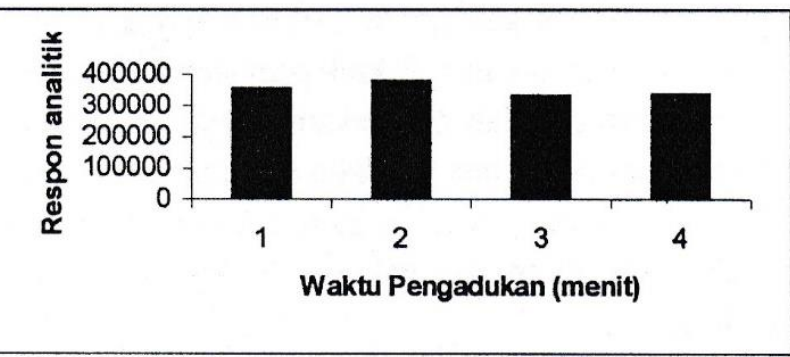

Gambar 2. Hasil respon analitik gas raksa (0) pada variasi waktu pengadukan

Hasil yang diperoleh pada variasi kadar $\mathrm{HCl}$ disajikan pada tabel 3 . 
Tabel 3. Hasil respon analitik gas raksa (0) pada variasi kadar $\mathrm{HCl}$

\begin{tabular}{|c|c|}
\hline KADAR HCI (\%) & RESPON ANALITIK \\
\hline 5 & 207157 \\
\hline 10 & 213556 \\
\hline 20 & 211092 \\
\hline 50 & 159588 \\
\hline
\end{tabular}

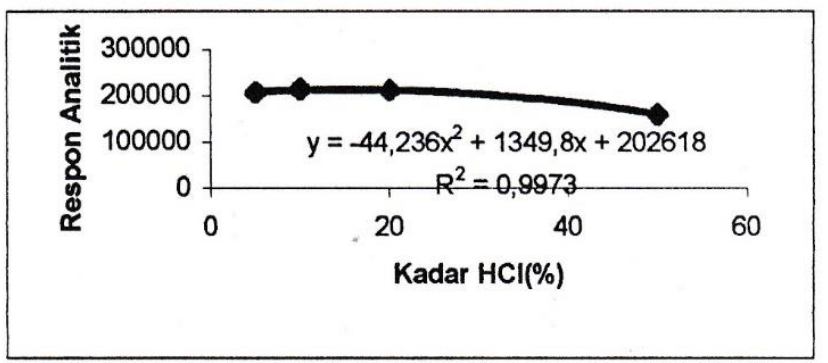

Gambar 3. Hasil respon analitik gas raksa (0) pada variasi kadar $\mathrm{HCl}$ (kadar $\mathrm{HCl}=15 \%$ )

Hasil yang diperoleh pada variasi kecepatan pompa penghisap disajikan pada tabel 4.

Tabel 4. Hasil respon analitik gas raksa (0) pada variasi kecepatan pompa penghisap

\begin{tabular}{|c|c|}
\hline $\begin{array}{c}\text { KECEPATAN POMPA } \\
\text { PENGHISAP (LMMNIT) }\end{array}$ & RESPON ANALITIK \\
\hline 0,3 & 377103 \\
\hline 0,5 & 367971 \\
\hline 1,0 & 142875 \\
\hline 1,5 & 89922 \\
\hline 2,0 & 62896 \\
\hline 2,5 & 45057 \\
\hline
\end{tabular}

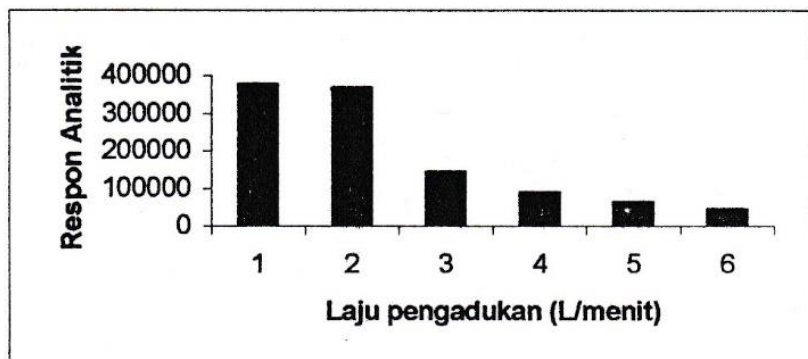

Gambar 4. Hasil respon analitik gas raksa (0) pada varias kecepatan pompa penghisap

\section{KESIMPULAN}

Kondisioptimum yang diperoleh adalah volume $\mathrm{SnCl}_{2}$ $5 \%$ sebanyak $1,5 \mathrm{~mL}$; waktu pengadukan 2 menit; lingkungan asam $5 \mathrm{~mL} \mathrm{HCl} 15 \%$ dan kecepatan pompa penghisap $0,3 \mathrm{~L} /$ menit.

\section{PUSTAKA}

1. Chou, H.N. dan Naleway, C.A., 1984, Determination of Mercury by Cold Vapour-Atomic Absorption Spectrometry, Anal. Chem. 56, 1737-1738,

2. Doolan, K.J., 1982, The Determination of Mercury in Solid Fuels by High Temperature Combustion and Cold
Vapour-Atomic Absorption Spectrometry, Anal. Chim. Acta 140,187-195.

3. El-Awad,, A.A., Miller, R.B. dan Carter, M.J., 1976, Automated Method for the Determination of Total and Inorganic Mercury in Water and Waste Water Samples, Anal. Chem. 48, 110-116.

4. Goto, M., Shibakawa, T., Arita, T. dan Ishii, D., 1982, Continuous Monitoring of Total and Inorganic Mercury in Waste Water and Other Water, Anal. Chim. Acta 140,179-185.

5. May, K., Stoeppler, M. dan Reisinger, K., 1987, Studies in the Ratio Total Mercury/Methyl Mercury in the Aquatic Food Chain, Toxicological and Enviromental Chemistry II, 153-159.

6. Powell, G.V.N., 1983, Industrial Effluents as a Source of Mercury Contamination in Terresterial Riparian Vertebrates, Environmental Pollution 5, 51-57.

7. Skoog, D.A., 1985, Principles of Instrumental Analysis, 3rd edition, Saunders College Publishing, Philadelphia. 
